Saudi Journal of Humanities and Social Sciences

Abbreviated Key Title: Saudi J Humanities Soc Sci

ISSN 2415-6256 (Print) | ISSN 2415-6248 (Online)

Scholars Middle East Publishers, Dubai, United Arab Emirates

Journal homepage: https://saudijournals.com

Original Research Article

\title{
Innovational Spirit under Capitalism: A New Critical Analysis of Main Street
}

\author{
Guo Lei ${ }^{1}, \mathrm{He} \mathrm{Li}^{2 *}$ \\ ${ }^{1}$ Professor of English Department, North China Electric Power University, China \\ ${ }^{2}$ Post-graduate student, majoring in English language and literature, North China Electric Power University, China
}

DOI: $10.36348 /$ sjhss.2021.v06i04.004

| Received: 23.02.2021 | Accepted: 12.04.2021 | Published: 18.04.2021

*Corresponding author: $\mathrm{He} \mathrm{Li}$

\section{Abstract}

Main Street written by Sinclair Lewis is rich in meaning and with high value. The existing research ranges from realism, modernism, and narrative techniques. However, the research on Main Street from the perspective of new criticism is limited to irony, which is only a part of the new criticism and is not sufficient and in-depth. Moreover, generally speaking, researching results are few. This paper tries to apply a new critical analysis of Main Street, including four dimensions-tradition and individual, structure and muscle, polysemy and non-generative - to explain innovational spirit. First, Main Street under the rebellious spirit has modernism and originality, which ensures the author's distinctive characteristics. Second, this paper explores the tension beauty of characters under the theme of rebellious spirit through quantitative analysis, due to its vividness, simplicity, universality and rationality. The plot tensions verify in case of structure and muscle, but literature features in both literariness and accuracy. Third, the ambiguity reflects the way in which tension presents, which is an indispensable part of literature. Fourth, innovational spirit gradually verifies from invisibility to visibility through character and rural culture, whose process is non-generative.

Keywords: innovational spirit, Main Street, quantitative, new criticism, tension.

Copyright () 2021 The Author(s): This is an open-access article distributed under the terms of the Creative Commons Attribution 4.0 International License (CC BY-NC 4.0) which permits unrestricted use, distribution, and reproduction in any medium for non-commercial use provided the original author and source are credited.

\section{INTRODUCTION}

As the First World War was far away from the American continent, the American economy developed unprecedentedly in the early 1920s. The United States quickly surpassed those old capitalist countries especially like Australia, the United Kingdom, and gradually became one of the strongest countries in the world. Main Street written by Sinclair Lewis focuses on depicting and revealing the dark side that widely exists in real life, that is, money covers everything. These people with similar thoughts and culture gather in different regions. They belong to different communities, like communities between the west and the east which have various cultures, habits, and so on. Community in thesis corresponds to a body of persons or nations having a shared history or common social, economic, and political interests. People are competing with each other. High commercialization quickly marginalizes interpersonal relationships, and an interpersonal trust crisis immediately emerges.
If there are any changes in the community, people hold different views. Webster defines the innovation a new thing or a new method of doing something. Innovational spirit refers to the group that people's attitude towards the change in community. Innovational spirit refers thoughts or attitude in people's mind concluding through their action. Innovational soul has apparent affinities for the people's attitude for the change in a community, the way they felt, what they felt.

The thesis begins our discussions with a series of propositions summarized and abstracted to a degree where they seem to axiomatic. First, Main Street is called as the masterpiece of satirical literature by many writers. Its writer Sinclair Lewis is regarded as the first brave man in the United States who dares to challenge traditional American literature. Second, Sinclair Lewis bravely subverts the poetic rural narrative respected by American writers and poets, and bitterly reveals and ridicules the existence of the rural life and cultural environment in the United States. Third, Sinclair Lewis uses practical writing techniques to reshape the 
authentic American villages and towns and the citizens living. All Americans can soberly face the natural changes in American towns, and wake up from their fantasies.

Currently, few papers give stage results of studies on Main Street under the literary theory, although paper results range from realism, modernism, and narrative techniques. Researchers over Main Street are few contrasted with American literature, which may account for the number of paper results. Moreover, from the perspective of new criticism, irony phenomenon has been observed, which is only a part of it and is not sufficient and in-depth. Therefore, dimensional analysis is not fully concerned. This paper tries to apply a new critical analysis of Main Street, including four dimensions-tradition and individual, structure and muscle, ambiguity and non-generative - to explain innovational spirit.

Based on the interdisciplinary study and the particularly innovative research, the author also needs to build its own new system and expands a new research area in poetic languages [1]. Therefore, another reason why the literary theory of Main Street is not wide enough is most of the existing studies interpret literature in three ways: author - centered, text centered and reader - centered. Research involves the text from realism, modernism, narrative ethics, and ecological criticism, while the study of new criticism is not involved or insufficient. Besides, literature is a kind of language construction. At the turn of twentieth century, there are trends with scholars appealing for the humanistic spirit, and against the anti-scientism. During this period, scholars tend to contrast the two based on pragmatism and technological levels [2]. But that doesn't mean the quantification analysis is irrational. Literary works has their formulas. The paper analyses Main Street through the quantitative research methods in applied linguistics from the inside of the novel, and combine the two interpretation methods to show the similarities and differences between quantitative research and literary research.

"Whatever the fiction combines, tension functions a lot. The essence of tension is that two or more forces depend on and restrict each other to form a certain balance. Tension is not only at the language level but also in the relationship between story and plot or between scene and image [3]". It is reflected in the tension field of structure, means, muscle quality, and effect on the restoration of innovational spirit. The thesis focuses on the study of Main Street from the literary technique tension.

Here are the types of tension: according to the language level, character tension; according to the deep level, plot tension, narrative techniques, irony, symbol, metaphor; according to research methods, quantitative tension and literary tension. Quantitative research controls various factors of a problem to be observed in the experimental environment and understand the relationship between factors by changing one or several factors. Various variables in quantitative research include independent variables, dependent variables, moderator variables, control variables, and intervening variables. The dependent variables function is also called function value. Some variable will change with the change of another (or other) variable that will change, called the dependent variables. Therefore, the thesis controls a variable factor and finds what happened to the dependent variables, whose relationship means the basic way the fiction generates. And then the paper further analyses how other variables like moderator variables and intervening variables influence the development of the plots. In the experiment, not every variable can participate in at the same time, therefore, control variables function. The paper would compare the findings over tension between criticisms, and then some new ideas may arise, which will build a connection between science and literature.

\section{Modernism and Originality of the Innovational Spirit in Main Street}

As a representative of new criticism, Eliot's tradition and personal ability refers to a description of unique characteristics with historical consciousness. In Main Street, modernism is shown as the action and behavior of the characters in the novel, with the color of history unconsciously. Carol Kennicott represents the reformists in the United States, while her husband Kennicott represents the Conservatives in the United States. 1920 is the most conservative year in the United States. Through the description, the author expresses his strong dissatisfaction which is against traditional dogma, and dare to challenge authority. The modernism has been observed with the portrayal of Carol Kennicott and Kennicott.

Originality which is another sign of originality of innovational spirit has been observed in Main Street. The people in Main Street say burglar expressions, which are different from the stereotype of traditional cowboys that are brave and adventurous. Born in a judge's family, Carol Kennicott is a beautiful, lively and romantic city girl. The middle class represented by Carol Kennicott rose rapidly after the American imperialism and actively participated. Simultaneously, her husband Kennicott was conservative, stubborn and not good at change, which limits the rural culture. In this paper, it is shown as traditional countryside and developed east. Different surroundings are one of the leading causes for thinking, which reflects modernism. They hold different ways of thinking. The former is to change the existing environment, and the latter is to adapt to the current climate. Their behavior is various. 


\section{Inner Life and Organic of Innovational Spirit in Main Street}

The meaning of poetry refers to its tension. Therefore, the basic written formula of Main Street based on the tension of the plot and then the way the pressure builds can be observed. This part will involve the quantitative plot tension.

\section{Quantitative plot tension}

The independent variable is the eastern bourgeois reform activities represented by Carol Kennicott, and the dependent variable is the future of Gopher Prairie, Minnesota. Carroll's bourgeois reform activities met with the conventional parties, and then she planned to transform the town by one person. She was not allowed by the conventional parties represented by the Philistines, and was monitored, rumored, seriously injured by them, and even not understood by his husband, Kennicott.

First, Carol Kennicott and Kennicott went to Gopher Prairie, Minnesota. The novel's plot revolves around two typical characters, a couple with opposite personalities, Carol Kennicott Milford's experience, and entanglement with Kennicott. Main Street tells the story of a beautiful, lively, and romantic eastern American city girl from the perspective of Carol Kennicott over the transformation of Gopher Prairie, Minnesota. After graduating from university, she married a pragmatic and conservative village doctor Kennicott and came to Gopher Prairie, Minnesota in the Midwest, where she lived well but had a dull atmosphere. Second, the moderating variable was the watcher, the victim and the slander of Gopher Prairie, Minnesota, and the second variable was the thought of Kennicott. She was not willing to waste her youth in leisure and was determined to transform Gopher Prairie, Minnesota. The tension of the plot goes through the process of balance tension rupture balance. Some of her most basic requirements like wearing, clothes, and so on were unsatisfied, which was not allowed by the conventional parties who resisted all changes. They did not hesitate to threaten her employing covert surveillance and slander. Surrounded by conventional parties, she felt lonely, confused, depressed and desperate. Third, she went back to the Eastern bourgeois culture represented by Washington to seek a way out and found that the stereotypes were the obstacles. The obstacle of conservative culture to bourgeois culture was finally swallowed by traditional culture. She found the crux there that the real enemy is not a few individuals, but those stereotypes. Forth, two years later, she returned to her husband and pinned her hopes on a great future, the year 2000. By analyzing of the change and interaction of various variables in the tension field, the paper can observe the tension effect of the tension of the plot tension and the combination of the two. Through the analysis, the author's effective control of the variables of different literary elements would be observed. Carol Kennicott's experience in Gopher Prairie, Minnesota divides into the following four stages: meeting Gopher Prairie, Minnesota, wanting to transform Gopher Prairie, Minnesota, disillusioning with conventional parties, and being internalized by conventional parties.

"The primary tension expresses in the form of suspense [3]". In Main Street, it refers to the tension of the gaiety and splendor between the metropolis and rural cities. The two types of culture are separately represented by Carol Kennicott and by Kennicott. Carroll sees the sharp differences and wants to change the Midwest culture with her action. The tension, here, is between Carroll's effort and the whole rural cultural change. In the next step, some tortuous plots, namely suspense will strengthen the basic tension and make this tension produce variation tension. "After a series of tension variations, tension continuously changes, so expectation suspense and sudden suspense are solved one by one [3]." The tension of plots instantly disappeared one by one. The failure of Carol Kennicott's transformation means that the balance of plot tension is broken. Main Street is composed of several narrative blocks, but the coherence and causality between the plots in the narration is not arranged in linear but with random. Therefore, "readers have the feelings of flashbacks and flashbacks in the narration which means the plots are not logical [3]". But compared with the theory of from balance to tension and to fracture, the basic plot differs in the ending in Main Street. The basic feelings to readers are the plot is like a ring to present, but not like a linear and is complicated. The basic formula from balance to tension and to fracture and then to balance analyzed by quantification method directs to the way the author presents the plot.

\section{Reasons of Different Critical Patterns between China and Western Countries}

The structure and mechanism of Main Street is a circular setting, that is "from balance to balance", which does not end with a reunion comedy often used in China. Instead, it shows the cruel reality to a higher degree with the possibility of truth. It takes the failure of bourgeois advanced culture of change as the structure to stimulate people to think about fact. The plot tension in Main Street shows patterns like "balance-tensionrupture-balance". And this plot mechanism is the most basic plot unit of a literary writing paradigm in different literary works. The whole structure mechanism highlights that the novel should be structure, rather than content or theme, which clearly emphasizes the uniqueness and importance of the text in literary criticism.

The different patterns are the representative of different thinking critic patterns of the researchers in China and the west. When appreciating literary works, scholars in China like to explore the ethical and moral values of literary works, focusing on preaching, while the West focuses on theoretical appreciation. "One 
reason involves the political education function of poetry which is especially emphasized by Confucianism and refers the thought that literature and art bear a heavy moral mission. Therefore, the theory of comparing morality, that is, poetry expressing ambition forms a basic concept in Chinese underlying awareness, which plays an essential part in the ethical understanding of the aesthetic object and the aesthetic tendency of the ethical object [4]". Preconceptions in the process of appreciating literary works should be avoided.

\section{The Complex Meaning of Innovational Sprit in Main Street}

Ambiguity is the complexity of thought. From the rhetorical point of view, ambiguity represents by symbolism, irony, details [5]. It divides into three categories: naming, image and detail. The literal meaning and symbolic meaning of poetic language coexist, and there is tension between them. Sinclair Lewis thoroughly attacked and criticized the "rural virus" by depicting the ugliness of the townspeople in Gopher Prairie, Minnesota, which is also a bad habit in cities and towns all over the United States. The most profound symbolic meaning of street does not damage the extension of literal expression; literal word gradually develops to name complex meaning that is the pronoun of conservative life in American society.

Another carrier of rich meanings is the metaphor, like Saloon, a composite culture organization and a representative of the middle class held by young ladies. From the 18th century to the middle of the 19th century, a plenty of small libraries scattered all over England, which promoted the issue of the national literary act enabling every tax payer the equal right to read. Similarly, during the nineteenth century, Chautaugud, a sign that American continuously sought self-improvement and highly industrialized society enters the information society partially [7]. But on the contrary, the women of middle class in Main Street read books with superficial understanding and just for fame and compliment. Therefore, optimal incentive scheme under information asymmetry is constructed and the ironic and ambiguity meaning of reading group and the innovational spirit are constructed through the contrast between women in Main Street and those in reality. Furthermore, at present, the phenomenon Chautaugud is similar the word involution which is caused by information asymmetry and will finally lead to the severe competition.

Critics also affirmed the ironic creation mode of Main Street. Sinclair Lewis' works are humorous and sensitive. He depicts all living beings on paper, especially the sharp point of dialogue. However, as far as the old writing style and the fabulous flavor are concerned, "Lewis' work is regarded as a more inferior. But according to critic Nabokov, Sinclair Lewis' work portraits the distortion of American soul in the unprecedented prosperity of American society and economy. His original writing style, unlike Howells' old realism American provided a new perspective of rural life [8]".

Generally speaking, paradigm can conclude the regularity of literary creation but cannot decrypt the ambiguity of language. Ambiguity is one writing skill to use less word to express more thoughts. "When people say that one thing is like another, they must have some properties that make them similar to each other [9]". What's more, it can make people calm down and think in peace. When readers read more than two incompatible literary elements, they will compare and find the logical connection between them. "In the literary process, reader's thinking goes back and forth between the different elements and multiple ideas integrate into new thoughts containing the whole value of the text. The internal conflicts are diversified and enriched through ambiguity. Whatever the forms of literary complex meanings are caused by ambiguity, metaphor or symbol, the same feature of them are the smallest unit with most information, including not only the literal meaning but also with inner meaning [10]". These words direct the aesthetic transcendence, which is the charming of the literature.

\section{Non-generative Process of Innovational Spirit in Main Street}

Main Street finally ends with Carroll's failure to change, presenting a situation in which conservative forces fight against stereotypes, showing the cities' attractiveness in the eastern United States. The existing studies also affirm the progressive nature of eastern culture from the perspective of recognizing countryside as rural virus. The unique characters and backgrounds described in the novel are rich in the special flavor of Midwest towns, especially the author's hometown. Sinclair Lewis is an expert in deliberately depicting the local life. In this sense, he can be called a local writer who plays up the local color. Another feature is that the theme expressed in Main Street is anti-traditional. Because in modern English literature and early American literature, many works describe innocent young people who leave their hometown to pursue golden or rosy dreams in a metropolis. As a result, they are either miserable or degenerated and destroyed; even if they get away with it, they become evil and ruthless. In short, the city is the source of all evils, while the countryside and towns maintain a kind and straightforward human nature. However, Sinclair Lewis's Main Street and some other works do the opposite. Taking the typical prairie town as the center, he exposed and ridiculed the Philistines' vulgarity, cruelty, greed, and prejudice with a sharp tone. There was a suffocating atmosphere around him. Simultaneously, he meticulously portrayed a city girl who was rich in education and ideals, determined to reform and finally assimilated by the turbid current. The 
theme is obvious: the city is beautiful, and the town is ugly [4].

The idea over the progressive nature of the eastern culture of the United States is not comprehensive but relative. The existence of rural culture without commercialization has its historical cognitive reasons, and it does not matter whether it is good or bad. Although critics define the theme of the street as a beautiful city and small-town, it does not prevent us from exploring the interaction between rural culture and urban and rural culture. After all, the spiritual core of America is not in civilization, but in the countryside. The Midwest, where agriculture still dominates, is the guardian of American rural culture. Although rural culture is backward and not fashionable, conservatism makes culture stagnate like a stopwatch, giving people a moment to appreciate it. Although Carroll's reform failed, she returned to her husband two years later and pinned her hopes on the great future. Still, it showed the two sides of rural culture, one side was backward compared with bourgeois commercial culture; the other side was highly inclusive compared with western culture. Although it was philistine and embarrassing, rural culture doesn't change. It is included in the urban culture. But in the long run, numerous actions like Carol Kennicott's action will push the rural life change one step by step.

The reader's feeling that one plot follows one plot isn't real, which presents non-generative character of innovational spirit. For example, "the novel is composed of several narrative blocks, the author does not deliberately show the coherence and causality between the plots in the narration, and there are flashbacks and flashbacks in the narration, so the stories are not logical" [3]. The rural culture is also constructed along with the portrayal of people's routine life. Although the novel writes in passive tone, it does present the rural culture which is warm and peaceful routine life full of rivalry. Therefore, whatever its plot or the rural culture of Gopher Prairie, Minnesota provides non-generative hints.

\section{RESULTS AND DISCUSSION}

The paper will clarify the results in the next and discuss the limits. First, the thesis enriches the theoretical research results of Main Street. A new critical analysis enhances the understanding of Main Street from the perspectives. For example, the Chautaugud has been observed. Second, "although literary research is challenging to be completely digitized, the paper can conduct empirical research on literary texts with the help of linguistic category concepts and research methods to help readers understand the process of literary creation, find the law of scholarly creation from the text, and provide a new perspective for literary analysis [3]". Therefore, the paper combines the theory of literary appreciation with quantitative research according to particular problems, and on the basis of literary theory to guarantee the unique features of literary works; the thesis carries out quantitative research on specific areas, which improves the cognition of the research object. Third, the application of the quantitative research method to interpret the text is only to clarify the basic paradigm, but literature has its own uniqueness which of is indispensable. This paper supplements the results of quantitative analysis from the complex meanings of innovational spirits. Fourth, the innovational spirit is the driving force to promote social change and has different styles in different writers' works, and it is unique, contemporary, non - generative, and aesthetic, showing the results completely.

A new critical analysis of Main Street pursues the organic unity of structure, which limits its understanding of meaning. After all, its perspectives are mainly in literary field. Therefore, a sociological critical analysis or even an exact quantification research has been observed. Although a new critical analysis has many disadvantages, it is essential and shall be not isolated from text. Therefore, researchers can focus more on quantitative methods and the critic theory to the novel analysis so as to further explore the connotative meaning.

\section{REFERENCES}

1. Liu, R. (2007). Constructing a New System of Poetic Languages_-A Review of Poetic Languages by Ma Dakang. Journal of Wenzhou University, 01, 113-116.

2. Zhang, W. (2021). The Four Kinds of Sublation by Which American New Criticism Constructs the Ontology of Literary Work. Journal of Social Science of Hunan Normal University, 01, 91 - 97.

3. Jiancheng, B. I. (2015). "Heterogeneous Confrontation" and "Dynamic Stillness": On the Literary Tension of Billy Bathgate from the Perspective of Quantitative Research. Foreign Language and Literature, 03.

4. Yang, X. (1988). A New Critical Analysis and the ancient Chinese poetics. Foreign Literature and Art Studies, 01:121-126.

5. Liu, Y. (2018). Ambiguity in Gou Moro's Novel. Journal of Gou Moruo Studies, 02, 67-70.

6. Hua, W. (2005). The Background and Significance of the Establishment of Public Libraries in England. Literary Journal, 01: 3- 9\& 19.

7. Chen, W. (1984). In Chautauqud, the 19th Century Lives Again. Shanghai Youth \& Children Research Center, 08, 30-32.

8. Sun, L. (1987). A meticulous and ironic painting: A Critical Review of Sinclair Lewis and Main Street. Foreign Literature Review, 01, 85-90 \& 72-72.

9. Cao, Li. (2020). William Empson: From Ambiguity to Complex Words. Foreign Literatures, 02, 22-31\& 156.

10. Yang, H. (2013). "Connotative and Denotative Meanings in Poetry" and "Tension Theory". Foreign Languages and Their Teaching, 03, 93 - 96. 